\title{
Stress Changes the Spatial Arrangement of Neurons and Glial Cells of Medial Prefrontal Cortex and Sertraline and Curcumin Prevent It
}

\author{
Ali Noorafshan ${ }^{1,2}$, Mohammad-Amin Abdollahifar ${ }^{2}$, and Saied Karbalay-Doust ${ }^{1,2} \bowtie$ \\ ${ }^{1}$ Histomorphometry and Stereology Research Centre, Shiraz University of Medical Sciences, Shiraz, Iran \\ ${ }^{2}$ Anatomy Department, School of Medicine, Shiraz University of Medical Sciences, Shiraz, Iran
}

\begin{abstract}
Objective The present study explored the three-dimensional spatial arrangements of the neurons and glial cells within the medial prefrontal cortex (mPFC) of rats.

Methods It evaluated the arrangement for differences after stress with or without treatment with curcumin and sertraline using second-order stereology. Orientator method was applied to obtain isotropic uniform random sections of mPFC. The pair correlation $\mathrm{g}(\mathrm{r})$ and cross-correlation functions were estimated by counting dipole probes superimposed on histological sections of mPFC.

Results The mean total volume of neurons and glial cells was $0.80(0.05)$ and $0.40(0.07)$, respectively in the control group. The corresponding values decreased by $50 \%$ in the stressed group. The curve of $g(r)$ for the neurons and glial cells showed a wider gap between the stressed rats' mPFC. Theses indicate a negative correlation (repulsion) between the neurons and glial cells in the stressed rats. Evaluation of the cross-correlation function of the neurons and glial cells also showed a negative correlation in the stressed group. The estimated values of the global degree of order in the spatial point pattern for neurons and glial cells were 0.62 and 0.20 in control and stressed animals, respectively. Curcumin and sertraline protected the spatial arrangements of the cells after stress induction in rats. In addition, the volume of the neurons and glial cells remained unchanged after stress.
\end{abstract}

Conclusion Dissociation of the neurons and glial cells can is seen at some places in the stressed rats' cortex. However, the spatial arrangement of the cells was remained unchanged in curcumin+stress and sertraline+stress rats. Psychiatry Investig 2015;12(1):73-80

Key Words Stress disorders, Cerebral cortex, Spatial analysis, Sertraline, Curcumin.

\section{INTRODUCTION}

Chronic stress induces structural and behavioral impairments. Chronic Variable Stress (CVS) has significant effects on the cellular integrity and function of certain brain areas, most especially the prefrontal cortex (PFC) and hippocampus of rats. ${ }^{1-3}$ Some studies have demonstrated that chronic restraint stress changed the morphological neurons in the medial PFC (mPFC) ${ }^{4,5}$ Although there are some reports regarding the quantitative aspects of the $\mathrm{mPFC}$, limited experiments

Received: October 26, 2013 Revised: March 9, 2014

Accepted: April 28, 2014 Available online: January 12, 2015

$\triangle$ Correspondence: Saied Karbalay-Doust, MSc

Histomorphometry and Stereology Research Centre, Shiraz University of Medical Sciences, Zand Ave., Shiraz 71348-45794, Iran

Tel: +98-711-2304372, Fax: +98-711-2304372,E-mail: karbalas@sums.ac.ir

(C) This is an Open Access article distributed under the terms of the Creative Commons Attribution Non-Commercial License (http://creativecommons.org/licenses/bync/3.0) which permits unrestricted non-commercial use, distribution, and reproduction in any medium, provided the original work is properly cited. have been performed on the spatial arrangement of the nervous system after stress. One study applied spatial pattern analysis carried out by investigation of the K-function which is essentially a combined count-distance measure. The results showed an altered spatial pattern of the neurons and glial cellsin the subjects with major depressive disorder in the PFC. ${ }^{6}$ Another study used the saucer method and also indicated that spatial arrangement of glial cells around neurons was different in various subregions of the human neocortex. ${ }^{7}$ The alterations in the spatial arrangement of the glial cells and the neurons may reflect functional changes in the relationship between them..$^{8-10}$ Therefore, at the first step, the present study aims to evaluate the spatial arrangement of the neurons and glial cells as well as their relationship after stress in rats. In the second step, a natural and a synthetic component; i.e., curcumin and sertraline, are prescribed and compared.

Curcumin is the principal curcuminoid of the popular Indian turmeric. It is the main component of curcuma longa and 
has been used in the Indian and Chinese systems of medicines. Nowadays, curcumin is being used for its diverse biological actions, such as antioxidant, anti-inflammatory, anticarcinogenic, anti-microbial, and neuroprotective effects. ${ }^{11-13}$ Sertraline is an antidepressant which is used to treat major depression in adult patients. Its antioxidant and neuroprotective action have also been reported in neuro degenerative diseases. $^{14}$

Therefore, the present research aims to evaluate the effects of chronic stress on the spatial arrangement of the neurons and glial cells in the mPFC of rats. The effect of application of curcumin and sertraline in these parameters will also be evaluated. We manipulated the PFC because depressed patients present differences in these cerebral structures. ${ }^{15}$ Briefly, the study was conducted to find responses to the following questions. How much does the spatial arrangement of neurons andglial cells and cross-correlation of the cells change after stress induction in mPFC of the rats? Can curcumin and sertraline prevent the possible changes in the spatial arrangement?

\section{METHODS}

\section{Animals}

In this study, 42 adult male Sprague-Dawley rats (240 to $280 \mathrm{~g}$ ) were obtained from the laboratory animal's center of Shiraz University of Medical Sciences, Shiraz, Iran. The Ethics Committee of the University approved the animal experiment (Approval No: 91-6124). The male rats were randomly assigned to experimental and control groups. The rats were housed under standard conditions, room temperature $\left(22-24^{\circ} \mathrm{C}\right)$, and a 12:12 h light-dark schedule and had free access to water and food. The study animals were divided into seven groups each containing 6 rats: Group I: stress+water group daily receiving stress and distilled water, Groups II: stress+olive oil group daily receiving stress and olive oil, Group III: curcumin group receiving curcumin (100 mg/kg/day) (Merck, Darmstadt, Germany), ${ }^{16,17}$ Group IV: sertraline group receiving sertraline (10 mg/kg/day) (Rouz Darou Pharmaceutical Company, Tehran, Iran, one of the limitations of this study was absence of the bioequivalence information of sertraline produced by the company), ${ }^{14}$ Group V: stress+curcumin group daily receiving stress and curcumin $(100 \mathrm{mg} / \mathrm{kg} /$ day $),{ }^{16,17}$ Group VI: stress+sertraline group daily receiving stress and sertraline (10 mg/kg/day) ${ }_{1}^{14}$ and GroupVII: control group. All the animals received daily gavages for 8 weeks. It should be mentioned that they were housed in plastic cages under standard conditions.

\section{Stress model}

The animals were submitted to a CVS regime over a 56- days period or remained in their home cages without stress manipulation. ${ }^{18}$ The CVS is described in Table 1.

\section{Tissue preparation}

The rats were deeply anesthetized and decapitated and the brains were exposed by an incision along the midline of the skull. A small amount of fixative was poured on the exposed brain immediately. The brains were removed and mPFC was identified according to atlas of Paxinos and Watson. ${ }^{19}$ Isotropic Uniform Random (IUR) sections are necessary for estimating some of the stereological parameters of the mPFC including studying the spatial arrangement of the cells. In this study, orientator method was applied to obtain the IUR sections. ${ }^{20}$ The $\mathrm{mPFC}$ pieces were sectioned at $4 \mu \mathrm{m}$ thickness and were then stained by cresyl violet $(0.1 \%$ in distilled water). It should be noted that the glial cells were distinguished from the neurons by their smaller size, lack of a nucleolus, and stained cytoplasm.

\section{Estimations of covariance}

The stereological objective is to estimate the local $3 \mathrm{D}$ arrangements of different tissue compartments within mPFC. A transparent lattice bearing a row of points was constructed to serve as a set of linear dipole probes. ${ }^{21-26}$ Each row consisted of 50 points and 49 equidistant intervals. The point interval corresponded to a distance of $2.6 \mu \mathrm{m}$ on the scale of the tissue. This distance was selected because it offers a sensible starting distance with reference to the size of the glial cells. Consequently, both end points of dipoles (DP) of class size $r=1$ (equivalent to $2.6 \mu \mathrm{m}$ ) have chances of being included within the same cell section. That was also true for the neurons. The lattice was superimposed on the live image on a monitor connected to a microscope (Nikon, E-200, Japan). It was set to be random in position and orientation in each field. For each mPFC, 11 trials (a total of 550 test points) were conducted. For every trial, the nature of the tissue component underlying each test point was noted and all this information was recorded on a $50 \times 11$ matrix printed as a blank table with 50 columns and 11 rows. Within the cells of this matrix, each point was coded as 1 (neuron), 2 (glial cell), and 3 (neuropil) (Figure 1). There after the data sets were analyzed using the software prepared in Histomorphometry and Stereology Research Centre, Shiraz, Iran. To estimate "Vv", "C(r)", and " $\mathrm{g}(\mathrm{r})$ ", the distance between the points (DP) ranged from $\mathrm{r}=0$ (equivalent to $0 \mu \mathrm{m}$ ) to $\mathrm{r}=49$ and the total distance was $49 \times 2.6=127.4 \mu \mathrm{m}$. The covariance of a component $(\mathrm{X})$ was estimated by the following equation:

$$
\mathrm{C}(\mathrm{r}) \mathrm{X}=\Sigma \mathrm{DP}(\mathrm{X}, \mathrm{r}) / \Sigma \mathrm{DP}(\text { ref, } \mathrm{r})
$$


Table 1. The protocol for induction of the chronic variable stress in 56 days for the rat model

\begin{tabular}{|c|c|c|c|}
\hline Day & Stressor applied & Day & Stressor applied \\
\hline 1 & Cold restraint $(1.5 \mathrm{~h})$ & 29 & Damp bedding (2 h) \\
\hline 2 & Inclination of home cages ( $4 \mathrm{~h}$ ) & 30 & No stressor applied \\
\hline 3 & Flashing light $(2 \mathrm{~h})$ & 31 & Water deprivation (24 h) \\
\hline 4 & Restraint (2 h) & 32 & Inclination of home cages ( $6 \mathrm{~h}$ ) \\
\hline 5 & Isolation & 33 & Flashing light $(2 \mathrm{~h})$ \\
\hline 6 & Isolation & 34 & Cold restraint $(2 \mathrm{~h})$ \\
\hline 7 & Isolation & 35 & Isolation \\
\hline 8 & Damp bedding ( $2 \mathrm{~h})$ & 36 & Isolation \\
\hline 9 & Inclination of home cages $(6 \mathrm{~h})$ & 37 & Isolation \\
\hline 10 & No stressor applied & 38 & Flashing light (3 h) \\
\hline 11 & Flashing light (2 h) & 39 & Damp bedding ( $2 \mathrm{~h}$ ) \\
\hline 12 & Water deprivation (24 h) & 40 & Restraint (3 h) \\
\hline 13 & Restraint $(3 \mathrm{~h})$ & 41 & Cold restraint (1.5 h) \\
\hline 14 & Damp bedding ( $3 \mathrm{~h})$ & 42 & Inclination of home cages ( $4 \mathrm{~h}$ ) \\
\hline 15 & Inclination of home cages ( $4 \mathrm{~h}$ ) & 43 & Flashing light (2 h) \\
\hline 16 & Cold restraint $(2 \mathrm{~h})$ & 44 & Restraint (2 h) \\
\hline 17 & Flashing light (3 h) & 45 & Isolation \\
\hline 18 & Restraint (2.5 h) & 46 & Isolation \\
\hline 19 & Damp bedding ( $3 \mathrm{~h})$ & 47 & Isolation \\
\hline 20 & Isolation & 48 & Damp bedding (2 h) \\
\hline 21 & Isolation & 49 & Inclination of home cages ( $6 \mathrm{~h}$ ) \\
\hline 22 & Isolation & 50 & No stressor applied \\
\hline 23 & Cold restraint (1.5 h) & 51 & Flashing light (2 h) \\
\hline 24 & Water deprivation $(24 \mathrm{~h})$ & 52 & Water deprivation (24 h) \\
\hline 25 & Inclination of home cages $(4 \mathrm{~h})$ & 53 & Restraint (3 h) \\
\hline 26 & Restraint (3 h) & 54 & Damp bedding (3 h) \\
\hline 27 & Flashing light (3 h) & 55 & Inclination of home cages ( $4 \mathrm{~h}$ ) \\
\hline 28 & Restraint (1 h) & 56 & Cold restraint $(2 \mathrm{~h})$ \\
\hline
\end{tabular}

where $\mathrm{DP}(\mathrm{X}, \mathrm{r})$ and $\mathrm{DP}$ (ref, $\mathrm{r}$ ) are the dipole length which hit the favored structure (neuron or glia) and the nervous tissue, respectively.

\section{Estimation of pair correlation function}

Although a useful statistical description of spatial arrangement can be given using covariance, it depends upon the volume fraction and, as a result, making comparisons may be problematic. The dependence on volume fraction can be overcome by estimating pair correlation function. ${ }^{21-26}$ Pair correlation function is the normalized covariance function obtained by dividing covariance by the reference value (squared volume fraction):

$$
\mathrm{g}(\mathrm{r})=\mathrm{C}(\mathrm{r}) / \mathrm{Vv}^{2}
$$

\section{Estimation of cross-covariance}

All the above description refers to the covariance for a single component with respect to itself. In a multi-component tissue, dipoles often hit two different phases simultaneous-

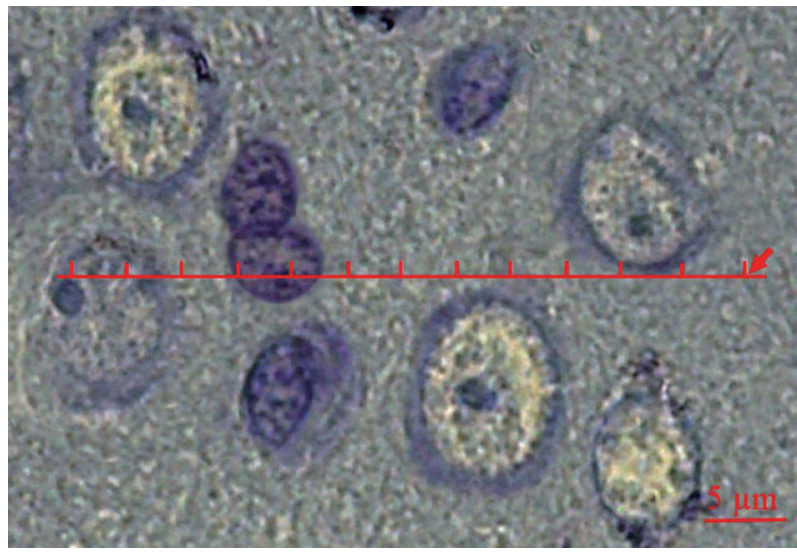

Figure 1. Coding of the cells for stereological estimation. A transparent lattice bearing one row of points was constructed to serve as a set of dipole probes. The point interval $(r)$ corresponded to a distance of $2.6 \mu \mathrm{m}$. Each test point was coded as 1,2, and 3 if the point was laid on the neurons, glia, and neuropil, respectively.

ly. ${ }^{21-26}$ The function used to quantify the spatial arrangement is cross-covariance $[\mathrm{C}(\mathrm{r}) \mathrm{X}, \mathrm{Y}]$ and can be estimated using the following equation: 


\section{$\mathrm{C}(\mathrm{r}) \mathrm{X}, \mathrm{Y}=\Sigma \mathrm{DP}(\mathrm{XY}, \mathrm{r}) / \Sigma \mathrm{DP}(\mathrm{ref}, \mathrm{r})$}

\section{Estimation of cross-correlation}

The cross-covariance between the two components (X, Y) is defined as the probability that an isotropic dipole of length " $\mathrm{r}$ " hits components $\mathrm{X}$ and $\mathrm{Y}$ simultaneously divided by the number of the dipoles hitting the reference volume. ${ }^{21-26}$ Similarly, the cross-covariance can be normalized to take out the volume fraction differences using the estimation of cross-correlation functions and the following equation:

\section{Estimation of degree of order}

In addition to correlation and cross-correlation, to estimate the degree of order of the neurons and glial cells in mPFC, the statistic "M" was estimated in both groups. It is related to the global degree of order in the spatial point pattern. ${ }^{25,26}$ This estimation includes identification of the $1^{\text {st }} \mathrm{g}_{\max }$ and the next following minimum $g_{\min }$ with the corresponding $r$-values $r_{\max }$ and $r_{\text {min }}$ (Figure 2) for each reduced g-function, where $r_{\min }>r_{\max }$. Using these data, the statistic will be estimated by the following formula:

$\mathrm{M}=\left(\mathrm{g}_{\max }-\mathrm{g}_{\min }\right) /\left(\mathrm{r}_{\min }-\mathrm{r}_{\max }\right)$
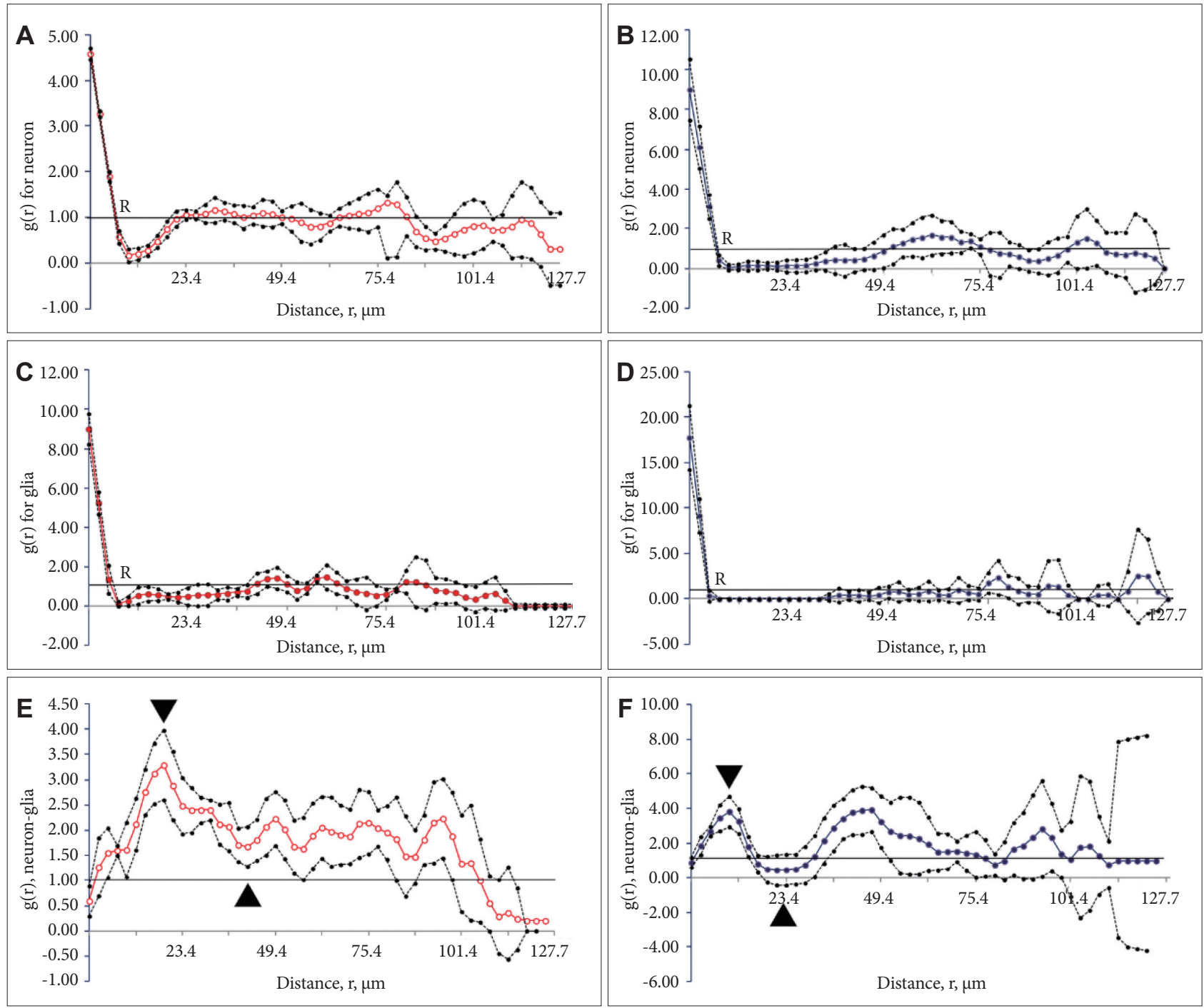

Figure 2. Pair correlation, and cross correlation functions $\mathrm{g}(\mathrm{r})$ of the neurons and glia. In each plot the mean over five cases is plotted with a point-wise confidence interval based on Students's t-distribution. The relationship between pair correlation function and dipole distance for neurons in the control $(A)$ and stress+distilled water $(B)$ rats. The horizontal reference (null hypothesis) line corresponded to the values expected for a random spatial arrangement $[g(r)=1]$. The pair correlation function approached closely to the reference line because no significant correlation was found between the values of points lying far away in the cortical tissue. The relationship between pair correlation function and dipole distance for glial cells in the control (C) and stress+distilled water groups (D). The cross-correlation, $g(r)$, between the neurons and glial cells plotted versus distance, $r$, in micrometers in the control $(E)$ and stress+distilled water $(F)$ groups. The dots are the mean $g(r)$ of the six animals in the control and stress+distilled water groups. The horizontal reference line at $g(r)=1.0$ is the reference line expected for a 'random' structure. " $\boldsymbol{\nabla}$ " and " $\boldsymbol{\Delta}$ " indicate $g_{\max }$ and $\mathrm{g}_{\min }$, respectively in both groups. 


\section{Statistics}

Group means and coefficients of variation among animals ( $\mathrm{CV}=$ standard deviation/mean) were calculated for neuron and glia volume within mPFC. Comparisons of $\mathrm{g}(\mathrm{r})$ of the neurons and glial cells and cross-correlation between the groups were undertaken using Mann-Whitney U-test.

\section{RESULTS}

\section{Volume}

The total volume $\left(\mathrm{mm}^{3}\right)(\mathrm{CV})$ of the neurons and glia was $0.80(0.05)$ and $0.40(0.07)$, respectively in the control group. The corresponding values for the stress+distilled water groups was $0.35(0.05)$ and $0.17(0.10)$, respectively, which were significantly different from the control group $(\mathrm{p}<0.05)$. No differences were seen between stress+distilled water vs. stress+olive oil. The volume in the group of curcumin or sertraline alone did not represent any significant differences in comparison with the control group. The volume of the neuron and glia showed significant differences in the stress+ sertraline or stress+curcumin groups in comparison with the stress+distilled water or stress+olive oil, respectively.

\section{Spatial arrangement of neurons}

Estimates of $\mathrm{g}(\mathrm{r})$ for the neurons are plotted against the dipole distances, $r$, in Figure 2A and B. The values at the beginning of the curve (from $\mathrm{r}=0$ to $5.2 \mu \mathrm{m}$ ) showed a difference between the control (A) and stress+distilled water groups. It then reduced and at a value of about $7 \mu \mathrm{m}$, indicated by letter " $R$ ", crossed the reference line. After dipping to the minimum value, the plot rose above the reference value again. In the control group, the curve crossed the line at $\mathrm{R}=7 \mu \mathrm{m}$ and rose at 23 $\mu \mathrm{m}$. In the stressed group, the corresponding values were $\mathrm{R}=7$ and $52 \mu \mathrm{m}$. As Figure 2 depicts, at these distances, the data points of the stressed rats went down below the reference line $[g(r)=1]$ indicating a significant negative correlation between the neurons. This means that they were neither arranged randomly nor clustered; rather, they were repulsed. However, this did not occur in the controls and repulsion could be detectedonly in a smaller distance. After the gap, the data points in both groups showed a random arrangement at larger distances $(\mathrm{p}<0.05)$. Therefore, the spatial arrangement of the neurons was changed by stress and dissociation of the neurons could be seen at some places. This indicates that the neurons are not normally arranged after stress. For better understanding of the plots, cell arrangements are presented in Figure 3. Figure $3 \mathrm{~A}$ and $\mathrm{B}$ show the arrangement of the neurons in the control and stress+distilled water groups, respectively. According to the results, fewer neurons and wider gaps were detected in the stressed rats. The evaluation of the $g(r)$ of the neuron of the control vs. stress+distilled water shows significant differences. No differences were seen between stress+distilled water vs. stress+olive oil. The group of curcumin or sertraline alone did not represent any significant differences in comparison with the control group. The $\mathrm{g}(\mathrm{r})$ of the neuron showed significant differences in the stress+sertraline or stress+curcumin groups in comparison with the stress+distilled water or stress+ olive oil, respectively.

\section{Spatial arrangement of the glial cells}

Estimates of $\mathrm{g}(\mathrm{r})$ for the glial cells are plotted against the dipole distances, $r$, in Figure $2 \mathrm{C}$ and D. As the plot shows, the curve crossed the reference line at $\mathrm{R}=5 \mu \mathrm{m}$ in both groups. However, it rose at 44 and $70 \mu \mathrm{m}$ in the control and stress+ distilled water groups, respectively. This indicates a wider gap between $\mathrm{R}$ and the reference line. It shows that the data points went down below the reference line $[\mathrm{g}(\mathrm{r})=1]$ indicating a significant negative correlation between the glial cells. This means that the glial cellswere repulsed in the stressed group but not

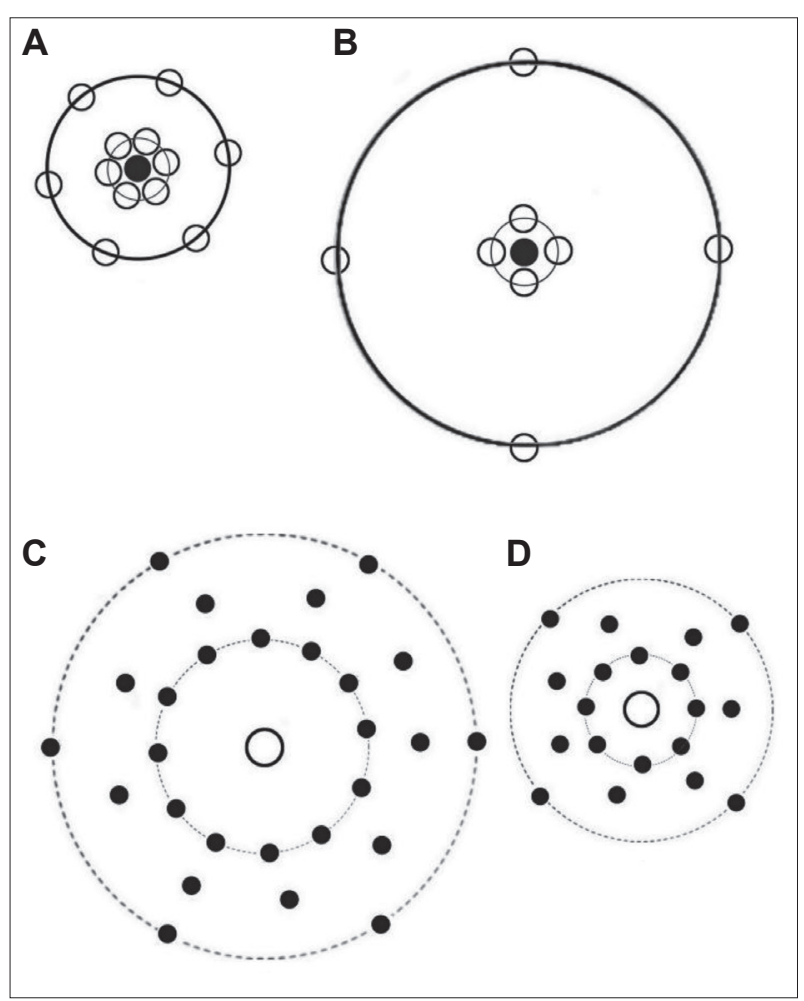

Figure 3. Cell spatial arrangement. For better understanding of the $g(r)$, cell arrangements are presented here. A and B show the arrangement of the neurons in the control and stress+distilled water groups, respectively. A fewer neurons (white circles) and wider gaps were arranged around the central neuron (black circle) in the stressed rats. Similar results were also obtained with regards to the glial cells. Bivariate assessments or the cross-correlation of the neurons and glial cells in the control and stress+ distilled water groups are presented in $C$ and $D$, respectively. More dispersion and repulsion of the glial cells (black circles) can be seen around the central neuron (white circle) in the stressed animals. 
in the controls. After the gap, the data points in both groups showed a pattern of random arrangement at larger distances $(\mathrm{p}<0.05)$. This can be considered as the dissociation of the glia at some places $\left(5^{-70} \mu \mathrm{m}\right)$. Hence, it can be concluded that the glial cells, similar to the neurons, are not normally arranged after stress.

The evaluation of the $\mathrm{g}(\mathrm{r})$ of the glial cells of the control vs. stress+distilled water showed significant differences. No differences were observed between stress+distilled water vs. stress+olive oil. The group of curcumin or sertraline alone did not represent any significant differences in comparison with the control group. The $\mathrm{g}(\mathrm{r})$ of the glial cells showed significant differences in the stress+sertraline or stress+curcumin groups in comparison with the stress+distilled water or stress+olive oil, respectively.

\section{Cross-correlation of the neurons and glial cells}

Figure $2 \mathrm{E}$ and $\mathrm{F}$ showed some differences in the spatial arrangement of the neurons and glia by plotting the cross-correlation function versus distance. The cross-correlation was zero at a distance of zero micrometer. By increasing the distances, the probability that the ends of a dipole could land in the two structures of interest increased, as well. If the crosscovariance is above the reference line, it indicates a positive correlation between the neuron and the glia. When it goes downward, however, it indicates a negative correlation. In this study, the cross-covariance was above the reference line in the control rats indicating a positive correlation between the neurons and glial cells. At $18-32 \mu \mathrm{m}$, both structures showed a negative correlation in the stress+distilled group, but not in the control rats. At $84-88 \mu \mathrm{m}$ also, a negative correlation was observed in the stress+distilled group in comparison to the control rats $(\mathrm{p}<0.05)$.

The curves began with ascending segment and there after attained positive values, mounting to a 1st maximum $\left(\mathrm{g}_{\max }\right)$ and then descending to a 1st minimum ( $\left.\mathrm{g}_{\min }\right)$ curve. According to Figure 2, the $g_{\max }$ and $g_{\min }$ in the curve of the control animals were about $r=21$ and $44 \mu \mathrm{m}$, respectively. On the other hand, the $g_{\max }$ and $g_{\min }$ for the stressed rats were about $r=10$ and $26 \mu \mathrm{m}$, respectively. As Figure 2 depicts, the height of the first maximum of the pair correlation function declined rapidly in the stressed group. This indicates a preferred distance between the two cells in the two groups. In other words, this distance indicates structural information about how neurons and glial cells within the mPFC are spatially changed relative to each other. The study findings revealed differences among the study groups regarding the bivariate assessments of the neurons and glia. For simplicity of understanding the crosscorrelation of the neurons and glial cells in the control and stress+distilled water groups are presented in Figure 3C and
$D$, respectively. More dispersion and repulsion can be seen in the stress+distilled water animals. Besides, plots of pair-correlation function of neurons and glia showed a wider gap in the spatial arrangement of these structures in the MPFC after chronic stress.

The evaluation of the cross-correlation of the neuron-glial cells of the control vs. stress+distilled water showed significant differences. No differences were observed between stress+ distilled water vs. stress+olive oil. The group of curcumin or sertraline alone did not represent any significant differences in comparison with the control group. The cross-correlation of the neuron-glial cells showed significant differences in the stress+sertraline or stress+curcumin groups in comparison with the stress+distilled water or stress+olive oil, respectively.

\section{Degree of order of the cells}

The statistic "M" was related to the global degree of order in the spatial point pattern. The estimated values for the neurons and glial cells were 0.62 and 0.20 in control and stressed animals, respectively.

\section{DISCUSSION}

In the current study, stereological methods were used to estimate the spatial arrangement of the neurons and glial cells of mPFC. The major advantage of this study was the unique quantification of the spatial pattern organization of the neuronal and glial cytoarchitecture. In a simple word according to the results, fewer neurons and wider gaps were detected in the stressed rats. Similar results were also obtained with regards to the glial cells. Bivariate assessments of the neurons and glia in the control and stress+distilled water groups showed more dispersion and repulsion in the stressed animals. Besides, plots of pair-correlation function of neurons and glia showed a wider gap in the spatial arrangement of these structures in the mPFC after chronic stress. Therefore, this gap should be filled with neuropil. However, our results supported the hypothesis that an altered pattern of neuronal and glial position is present in the mPFC after chronic stress. There are reports that explain morphometric changes for neuronal and glial cells density and size in prefrontal cell of major depression patients. ${ }^{5,6}$ Our previous study revealed a difference in the cellular spatial patterns in dorsal root ganglion of sciatic nerve crush. ${ }^{27}$ The present study showed alterations in neurons and glial cells arrangement, as well. In general, investigation of the spatial arrangement may provide interesting data about the structural changes that cannot be detected using first order stereology. For instance, Hof et al. performed a stereologic analysis of the spatial distribution of oligodendrocytes in layer III of Brodmann's area 9 in the superior fron- 
tal gyrus in schizophrenia. Their results suggested a change in the spatial distribution of oligodendrocytes in schizophrenia. ${ }^{28}$ Thus, assessment of spatial arrangement should be considered in future investigations.

The changes in the spatial arrangement of the neurons and glia might be related to the cell loss in the cortex. This cell loss can be explained according to our previous study which showed that chronic exposure to stress reduced the volume as well as the number of neurons and glial cells in the MPFC (accepted for publishing). Several mechanisms might be responsible for neuron or glail loss in the mPFC. The previous data reported that chronic stress, in addition to suppressing neurogenesis, may also trigger apoptosis. ${ }^{29,30}$ In addition it was shown that the cortical neurons are sensitive to neurotransmitter level changes in the tissue. ${ }^{29,30}$ Low but persistent levels of glutamate or other excitatory amino acids such as $\mathrm{N}$-methyl-d-aspartate, have been shown to cause apoptosis. ${ }^{29,30}$ On the other hand, the apoptotic neurons seen after chronic stress may express glucocorticoid receptors. ${ }^{29,30}$ In addition apoptosis is also caused by the pro-inflammatory cytokine interleukin 1- $\beta$ whose expression has been shown to increase by chronic stress. ${ }^{29,30}$ Therefore, chronic stress -induced apoptosis may be the result of glucocorticoids working in collaboration with inflammatory cytokines and excitatory amino acids. It has been shown that chronic stress resulted in edema around all types of blood vessels, tortuous blood vessels and dramatic impairments in microcirculation. ${ }^{31}$

Recent data have recommended that the therapeutic action of antidepressants may include their effect on neuronal survival. In fact, antidepressants decrease tissue atrophy in depressed patients, as well as in animal models of depression. ${ }^{32}$ The findings obtained from animal studies have also suggested that many of the changes can be reversed by antidepressant treatment. ${ }^{33-35}$ In this study, we evaluated the effect of the chronic administration of curcumin and sertraline on the stereological parameters altered by stress. The present study showed that the changes in spatial arrangement of the cells were protected by sertraline. The previous studies indicated that curcumin shows antidepressant like action. ${ }^{33-35}$ It has been also used in major depression as well as inhibitor of monoamine oxidase enzyme. Curcumin can also regulate the level of various neurotransmitters and promotes hippocampal neurogenesis. ${ }^{11}$ Our results demonstrated that curcumin prevented the change in the spatial pattern of the neurons to glial cells in the mPFC after chronic stress. In another study, curcumin was shown to protect the dopamine producing cells of the substantial nigra area of the brain in a rat model of Parkinson's disease. ${ }^{11}$ Besides, various reports have suggested the beneficial effects of sertraline in animal models of depression. ${ }^{36-38}$ Several studies reported that antidepressant admin- istration prevented both hippocampal atrophy and altered neurogenesis in the dentate gyrus induced by stress. ${ }^{39}$ Our previous study showed that stress affected the behavioral tests, such as spatial learning, memory, anxiety, and anhedonia. ${ }^{16}$ However, the pathogenesis of neurons and glial cells after chronic stress is still controversial. Yet, this method can provide useful data in investigation of different structures in $\mathrm{mPFC}$ after chronic stress.

In case of interpretation of the spatial arrangement graph, it should be mentioned that the behavior of near the origin may depend to an important extent on the actual size of the cells. That is, for small a dipole will often lay within the same cell; it may not often hit two cells. It is therefore might be some degree of uncertainty to conclude that, if is large for small, then the cells tend to be close together, as suggested by Figure $3 \mathrm{~A}$ and $\mathrm{B}$. In general, a weakness of second order methods is that it is much easier to interpret the shape of a graph after seeing the real pattern. In other words, it generally needs care to infer a pattern from a graph.

\section{Conclusion}

The findings of the current study showed a difference between the stressed and the control group regarding the cellular spatial patterns in $\mathrm{mPFC}$ of the rats exposed to chronic stress. A dissociation (a gap) was observed between the neurons and glial cells in mPFC after chronic stress. The findings also demonstrated that curcumin and sertraline could eliminate the adverse effects of stress on spatial arrangement at mPFC.

\section{Acknowledgments}

This work was performed at Histomorphometry and Stereology Research Centre, Shiraz University of Medical Sciences, Shiraz, Iran. This study is a part of the thesis written by Mohammad-Amin Abdollahifar, $\mathrm{PhD}$ student of Anatomy. The work was financially supported by the Research Vice-chancellor of Shiraz University of Medical Sciences (Grant No. 91-6124). The authors would like to appreciate Rouz Darou Pharmaceutical Company for their kind provision of sertraline. They are also grateful for Ms. A. Keivanshekouh at the Research Improvement Center of Shiraz University of Medical Sciences for improving the use of English in the manuscript.

\section{REFERENCES}

1. Heim C, Owens MJ, Plotsky PM, Nemeroff CB. The role of early adverse life events in the etiology of depression and posttraumatic stress disorder. Focus on corticotropin-releasing factor. Ann N Y Acad Sci 1997;821:194-207.

2. Joëls M, Karst H, Krugers HJ, Lucassen PJ. Chronic stress: implications for neuronal morphology, function and neurogenesis. Front Neuroendocrinol 2007;28:72-96.

3. Kendler KS, Kessler RC, Walters EE, MacLean C, Neale MC, Heath AC, et al. Stressful life events, genetic liability, and onset of an episode of major depression in women. Am J Psychiatry 1995;152:833-842.

4. Akana SF, Chu A, Soriano L, Dallman MF. Corticosterone exerts sitespecific and state-dependent effects in prefrontal cortex and amygdala on regulation of adrenocorticotropic hormone, insulin and fat depots. 
J Neuroendocrinol 2001;13:625-637.

5. Rajkowska G, Miguel-Hidalgo JJ, Wei J, Dilley G, Pittman SD, Meltzer HY, et al. Morphometric evidence for neuronal and glial prefrontal cell pathology in major depression. Biol Psychiatry 1999;45:1085-1098.

6. Cotter D, Mackay D, Landau S, Kerwin R, Everall I. Reduced glial cell density and neuronal size in the anterior cingulate cortex in major depressive disorder. Arch Gen Psychiatry 2001;58:545-553.

7. Stark AK, Gundersen HJ, Gardi JE, Pakkenberg B, Hahn U. The saucor, a new stereological tool for analysing the spatial distributions of cells, exemplified by human neocortical neurons and glial cells. J Microsc 2011;242:132-147.

8. Berry M, Butt M. Structure and Function of Glia in the Central Nervous System (6th Edition). In: Graham DI, Lantos P, Editors. Green Fields Neuropathology. New York: The Oxford University Press, 1997, p.63-83.

9. Araque A, Parpura V, Sanzgiri RP, Haydon PG. Tripartite synapses: glia, the unacknowledged partner. Trends Neurosci 1999;22:208-215.

10. Ullian EM, Sapperstein SK, Christopherson KS, Barres BA. Control of synapse number by glia. Science 2001;291:657-661.

11. Kulkarni S, Dhir A, Akula KK. Potentials of curcumin as an antidepressant. Scientific World Journal 2009;9:1233-1241.

12. Brouet I, Ohshima H. Curcumin, an anti-tumour promoter and antiinflammatory agent, inhibits induction of nitric oxide synthase in activated macrophages. Biochem Biophys Res Commun 1995;206:533-540.

13. Noorafshan A, Ashkani-Esfahani S. A review of therapeutic effects of curcumin. Curr Pharm Des 2013;19:2032-2046.

14. Yildirim E, Erol K, Ulupinar E. Effects of sertraline on behavioral alterations caused by environmental enrichment and social isolation. Pharmacol Biochem Behav 2012;101:278-287.

15. Lorenzetti V, Allen NB, Fornito A, Yücel M. Structural brain abnormalities in major depressive disorder: a selective review of recent MRI studies. J Affect Disord 2009;117:1-17.

16. Noorafshan A, Abdollahifar MA, Karbalay-Doust S, Asadi-Golshan R, Rashidian-Rashidabadi A. Protective effects of curcumin and sertraline on the behavioral changes in chronic variable stress-induced rats. Exp Neurobiol 2013;22:96-106.

17. Noorafshan A, Asadi-Golshan R, Karbalay-Doust S, Abdollahifar MA, Rashidiani-Rashidabadi A. Curcumin, the main part of turmeric, prevents learning and memory changes induced by sodium metabisulfite, a preservative agent, in rats. Exp Neurobiol 2013;22:23-30.

18. Tagliari B, Noschang CG, Ferreira AG, Ferrari OA, Feksa LR, Wannmacher CM, et al. Chronic variable stress impairs energy metabolism in prefrontal cortex and hippocampus of rats: prevention by chronic antioxidant treatment. Metab Brain Dis 2010;25:169-176.

19. Paxinos G, Watson C. The Rat Brain in Stereotaxic Coordinates. San Diego: Academic Press; 2007.

20. Mattfeldt T, Mall G, Gharehbaghi H, Möller P. Estimation of surface area and length with the orientator. J Microsc 1990;159:301-317.

21. Krasnoperov RA, Stoyan D. Second-order stereology of spatial fibre systems. J Microsc 2004;216:156-164.

22. Reed MG, Howard CV, DE Yanés GS. One-stop stereology: the estimation of 3D parameters using isotropic rulers. J Microsc 2010;239:
54-65.

23. Mayhew TM. Second-order stereology and ultrastructural examination of the spatial arrangements of tissue compartments within glomeruli of normal and diabetic kidneys. J Microsc 1999;195:87-95.

24. Mayhew TM. Quantitative description of the spatial arrangement of organelles in a polarised secretory epithelial cell: the salivary gland acinar cell. J Anat 1999;194:279-285.

25. Mattfeldt T, Eckel S, Fleischer F, Schmidt V. Statistical analysis of reduced pair correlation functions of capillaries in the prostate gland. J Microsc 2006;223:107-119.

26. Mattfeldt T, Frey H, Rose C. Second-order stereology of benign and malignant alterations of the human mammary gland. J Microsc 1993; 171:143-151.

27. Noorafshan A, Omidi A, Karbalay-Doust S, Aliabadi E, Dehghani F. Effects of curcumin on the dorsal root ganglion structure and functional recovery after sciatic nerve crush in rat. Micron 2011;42:449-455.

28. Hof PR, Haroutunian V, Friedrich VL Jr, Byne W, Buitron C, Perl DP, et al. Loss and altered spatial distribution of oligodendrocytes in the superior frontal gyrus in schizophrenia. Biol Psychiatry 2003;53:1075-1085.

29. Bachis A1, Cruz MI, Nosheny RL, Mocchetti I. Chronic unpredictable stress promotes neuronal apoptosis in the cerebral cortex. Neurosci Lett 2008;442:104-108.

30. Lucassen PJ, Vollmann-Honsdorf GK, Gleisberg M, Czeh B, De Kloet ER, Fuchs E. Chronic psychosocial stress differentially affects apoptosis in hippocampal subregions and cortex of the adult tree shrew. Eur J Neurosci 2001;14:161-166.

31. Tishkina AO, Levshina IP, Lazareva NA, Passikova NV, Stepanichev MY, Ajrapetyanz MG, et al. Chronic stress induces nonapoptotic neuronal death in the rat hippocampus. Dokl Biol Sci 2009;428:403-406.

32. Czeh B, Michaelis T, Watanabe T, Frahm J, de Biurrun G, van Kampen $\mathrm{M}$, et al. Stress-induced changes in cerebral metabolites, hippocampal volume, and cell proliferation are prevented by antidepressant treatment with tianeptine. Proc Natl Acad Sci U S A 2001;98:12796-12801.

33. Henn FA, Vollmayr B. Neurogenesis and depression: etiology or epiphenomenon? Biol Psychiatry 2004;56:146-150.

34. Joëls M, Karst H, Alfarez D, Heine VM, Qin Y, van Riel E, et al. Effects of chronic stress on structure and cell function in rat hippocampus and hypothalamus. Stress 2004;7:221-231.

35. Sapolsky RM. Glucocorticoids and hippocampal atrophy in neuropsychiatric disorders. Arch Gen Psychiatry 2000;57:925-935.

36. Matar MA, Cohen H, Kaplan Z, Zohar J. The effect of early poststressor intervention with sertraline on behavioral responses in an animal model of post-traumatic stress disorder. Neuropsychopharmacology 2006;31:2610-2618.

37. Santarelli L, Saxe M, Gross C, Surget A, Battaglia F, Dulawa S, et al. Requirement of hippocampal neurogenesis for the behavioral effects of antidepressants. Science 2003;301:805-809.

38. Malberg JE, Eisch AJ, Nestler EJ, Duman RS. Chronic antidepressant treatment increases neurogenesis in adult rat hippocampus. J Neurosci 2000;20:9104-9110.

39. Gould E, Tanapat P. Stress and hippocampal neurogenesis. Biol Psychiatry 1999;46:1472-1479. 